\title{
ANALISIS TINGKAT KEBERHASILAN PELAKSANAAN PROGRAM SANITASI TOTAL BERBASIS MASYARAKAT (STBM) DI WILAYAH KERJA PUSKESMAS MANGANITU KABUPATEN KEPL. SANGIHE (Studi Di Desa Taloarane I)
}

\author{
Poltje D. Rumajar ${ }^{1)}$, Dismo Katiandagho ${ }^{2)}$ Daniel Robert ${ }^{3)}$ \\ ${ }^{1,2)}$ Jurusan Kesehatan Lingkungan Poltekkes Kemenkes Manado \\ ${ }^{3)}$ Jurusan Gizi Poltekkes Kemenkes Manado \\ Email : desmonk80@gmail.com
}

\begin{abstract}
As a result of the preliminary survey at the Manganitu Health Center, there were 18 villages and all villages implementing the Community Based Total Sanitation program. In 2017 from 18 villages, only 2 villages had declared STBM programs with 5 pillars, namely Hiung and Talaorane villages I. For triggering Community Based Total Sanitation has been carried out by 16 other villages but has not implemented the declaration. The aim of the study was to analyze the level of success of the implementation of theProgram Community Based Total Sanitation in the Manganitu Community Health Center Working Area. This research is included in descriptive research. The population is all villages in the work area of the Manganitu Community Health Center as many as 18 villages, and the sample is the people who have carried out triggering and have implemented the declaration Stop defecating carelessly, namely the people in Taloarane I, Manganitu District, Sangihe Islands Regency. The results of the study were that the level of satisfaction with the program was Community Based Total Sanitation Pillar I80\% of respondents were satisfied and 20\% of respondents were not satisfied. The success ofProgram was theCommunity Based Total Sanitation Pillar I93.3\% of the program was Community Based Total Sanitation successful and only $6.7 \%$ of the program Community Based Total Sanitation was unsuccessful. Conclusion: The level of satisfaction with the program Community Based Total Sanitation Pillar Iis $80 \%$ of respondents were satisfied and $20 \%$ of respondents were not satisfied. The success ofProgram was theCommunity Based Total Sanitation Pillar I 93.3\% of the program was Community Based Total Sanitation successful and only $6.7 \%$ of the program Community Based Total Sanitation was unsuccessful. Suggestion: For Manganitu Community Health Center to always evaluate the community who still dispose of feces in the river, and always provide information about the dangers and adverse effects on health and the environment if they dispose of feces in the river and for the Taloarane I Village Government, Manganitu District to provide assistance, reprimand and sanctions for people who always throw feces in the river.
\end{abstract}

Keywords: success of Community-Led Total Sanitation Pillar I, Stop Bowel Sembarangan

\begin{abstract}
Abstrak. Hasil survey pendahuluan di Puskesmas Manganitu, terdapat 18 desa dan semua desa melaksanakan program Sanitasi Total Berbasis Masyarakat (STBM). Pada tahun 2017 dari 18 desa, baru 2 desa yang telah mendeklarasikan program STBM dengan 5 pilar, yaitu desa Hiung dan Talaorane I. Untuk pemiciuan STBM sudah dilaksanakan oleh 16 desa yang lain tetapi belum melaksanakan deklarasi. Tujuan penelitian yaitu untuk menganalisis tingkat keberhasilan pelaksanaan Program STBM di Wilayah Kerja Puskesmas Manganitu. Penelitian ini termasuk dalam penelitian deskriptif. Poulasi adalah Semua desa yang ada di wilayah kerja Puskesmas Manganitu sebanyak 18 desa, dan yang menjadi sampel yaitu masyarakat yang sudah melaksanakan pemicuan dan sudah melaksanakan deklarasi Stop BABS yaitu masyarakat yang ada di Taloarane I Kecamatan Manganitu Kabupaten Kepulauan Sangihe. Hasil penelitian yaitu Tingkat kepuasan terhadap program STBM Pilar I yaitu $80 \%$ responden merasa puas dan 20\% responden tidak merasa puas. Keberhasilan Program STBM Pilar I yaitu 93,3\% program STBM berhasil dan hanya 6,7\% program STBM tidak berhasil. Kesimpulan : Tingkat kepuasan terhadap program STBM Pilar I yaitu $80 \%$ responden merasa puas dan 20\% responden tidak merasa puas. Keberhasilan Program STBM Pilar I yaitu 93,3\% program STBM berhasil dan hanya 6,7\% program STBM tidak berhasil. Saran : Bagi Puskesmas Manganitu agar selalu melakukan evaluasi bagi masyarakat yang masih membuang tinja di sungai, dan selalu memberikan penyuluhan tentang bahaya serta dampak buruk bagi kesehatan dan lingkungan jika membuang tinja di sungai dan bagi Pemerintah Desa Taloarane I Kecamatan Manganitu agar memberikan pendampingan, teguran dan sanksi bagi masyarakat yang selalu membuang tinja di sungai.
\end{abstract}

Kata Kunci : Keberhasilan STBM Pilar I, Stop BABS

Permasalahan kesehatan lingkungan yang mendominasi adalah masalah sanitasi. Tantangan pembangunan sanitasi di Indonesia adalah sosial budaya dan perilaku penduduk yang terbiasa buang air besar di sembarang tempat, khususnya 
ke badan air yang juga digunakan untuk mencuci, mandi dan kebutuhan lainnya.

Salah satu upaya pemerintah dalam meningkatkan derajat kesehatan masyarakat adalah melalui program nasional Sanitasi Total Berbasis Masyarakat (STBM).

Peraturan Menteri Kesehatan Republik Indonesia Nomor 3 Tahun 2014 tentang Sanitasi Total Berbasis Masyarakat, bahwa dalam rangka memperkuat upaya perilaku hidup bersih dan sehat, mencegah penyebaran penyakit berbasis lingkungan, meningkatkan kemampuan masyarakat, serta meningkatkan akses air.

Pelaksanaan Sanitasi Total Berbasis Masyarakat (STBM) dengan lima pilar (Stop Buang air besar Sembarangan, Cuci Tangan Pakai Sabun, Pengelolaan Air Minum dan Makanan Rumah Tangga, Pengamanan Sampah Rumah Tangga, dan Pengamanan Limbah Cair Rumah Tangga) akan mempermudah upaya meningkatkan akses sanitasi masyarakat yang lebih baik serta mengubah dan mempertahankan keberlanjutan budaya hidup bersih dan sehat. Pelaksanaan program STBM dimulai dari pilar pertama yaitu Stop Buang Air Besar Sembarangan (Stop BABS). Fokus pertama dilakukan pada Stop BABS karena pilar tersebut berfungsi sebagai pintu masuk menuju sanitasi total serta merupakan upaya untuk memutus rantai kontaminasi kotoran manusia terhadap air baku minum, makanan, dan lainnya (Ditjen PP dan PL, 2011).

Tersedianya jamban merupakan usaha untuk memperbaiki sanitasi dasar dan dapat memutus rantai penularan penyakit. Jamban merupakan tempat yang aman dan nyaman untuk digunakan sebagai tempat buang air besar. Jamban sehat adalah fasilitas pembuangan tinja yang mencegah kontaminasi ke badan air, kontak antara manusia dan tinja, bau yang tidak sedap, membuat tinja tidak dapat dihinggapi serangga, serta binatang lainnya, dan konstruksi dudukannya dibuat dengan baik, aman, dan mudah dibersihkan (Nugraha, 2015).

Program STBM ini lebih menekankan pada perubahan perilaku kelompok masyarakat dengan pemicuan menggunakan metode Metodology Participatory Assesmant Participatory Hygiene And Sanitation Transformasi (MPAPHAST). Pemicuan dilaksanakan dengan cara fasilitasi kepada masyarakat dalam upaya memperbaiki keadaan sanitasi di lingkungan mereka hingga mencapai kondisi Open Defecation Free (ODF). Kondisi ODF ditandai dengan 100\% masyarakat telah mempunyai akses BAB di jamban sendiri, tidak adanya kotoran di lingkungan mereka, serta mereka mampu menjaga kebersihan jamban (Permenkes No.3 Tahun 2014).

Hasil survey pendahuluan di Puskesmas Manganitu, terdapat 18 desa dan semua desa melaksanakan program STBM. Pada tahun 2017 dari 18 desa, baru 2 desa yang telah mendeklarasikan program STBM dengan 5 pilar, yaitu desa Hiung dan Talaorane I. Berdasarkan latar belakang masalah tersebut di atas maka penulis melakukan penelitian tentang analisis tingkat keberhasilan pelaksanaan Program Sanitasi Total Berbasis Masyarakat (STBM) di Wilayah Kerja Puskesmas Manganitu (Studi Di Desa Taloarane I). Tujuan penelitian ini yaitu untuk mengnalisis tentang tingkat keberhasilan pelaksanaan Program Sanitasi Total Berbasis Masyarakat (STBM) di Wilayah Kerja Puskesmas Manganitu (Studi Di Desa Taloarane I).

\section{Metode}

Jenis Penelitian penelitian ini termasuk dalam penelitian deskriptif Penelitian ini dilaksanakan pada bulan September - Oktober 2018 di Desa Taloarane I Wilayah kerja Puskesmas Manganitu Kabupaten Kepulauan Sangihe. Populasi dalam penelitian ini yaitu semua desa yang ada di wilayah kerja Puskesmas Manganitu sebanyak 18 desa. Yang menjadi sampel pada penelitian ini yaitu masyarakat yang sudah melaksanakan pemicuan dan sudah melaksanakan deklarasi Stop BABS yaitu masyarakat yang ada di Taloarane I Kecamatan Manganitu Kabupaten Kepulauan Sangihe. Sampel dalam penelitian ini diambil dari anggota rumah tangga (setiap orang yang dapat berkomunikasi dengan baik) yaitu 45 rumah yang sudah dibangun jamban oleh pemerintah Desa Taloarane I Kecamatan Manganitu.

Data hasil penelitian dianalisis deskriptif terhadap hasil evaluasi pelaksanaan STBM Pilar I bagi masyarakat yang sudah melakukan deklarasi Stop BABS. Data hasil penelitian disajikan dalam bentuk narasi dan ditunjang oleh 
penyajian dengan menggunakan grafik dan tabel nilai dari hasil analisis data.

\section{Hasil}

Hasil penelitian yang dilakukan di Desa Taloarane I Kecamatan Manganitu Kabupaten Kepulauan. Sangihe, tentang evaluasi pelaksanaan STBM Pilar 1 yaitu stop buang air besar sembarangan, dapat diuraikan sebagai berikut :
1. Demografi Desa Taloarane I Kecamatan Manganitu

Desa Taloarane I Kecamatan Manganitu dibagi kedalam III Lindongan/ Dusun, dengan jumlah penduduk sebanyak 573 jiwa, yang terdiri dari 264 orang lakilaki (46\%) dan 309 orang perempuan (54\%) serta 157 kepala keluarga. Distribusi jumlah penduduk Desa Taloarane I berdasarkan jenis kelamin dapat dilihat pada Gambar 1 di bawah ini :

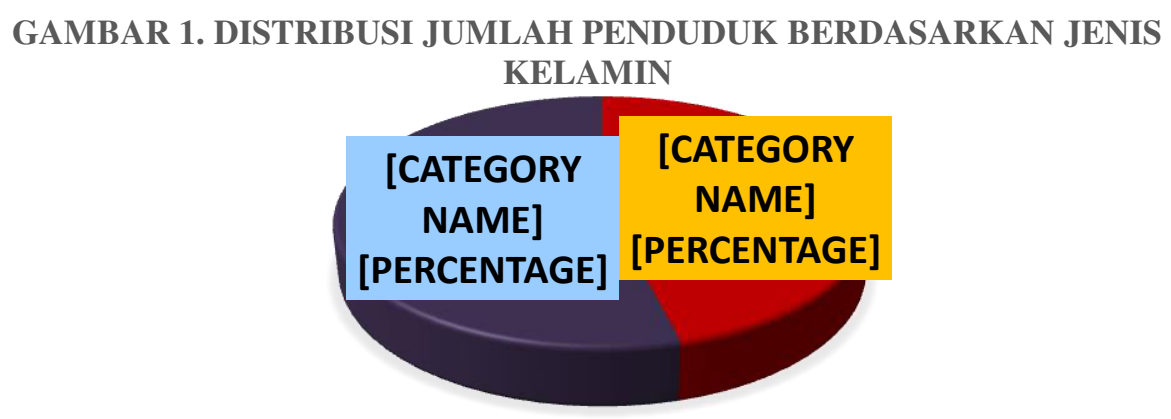

Jenis pekerjaan dari penduduk Desa Taloarane I Kecamatan Manganitu, paling banyak adalah petani sebanyak 142 orang (25\%) dan paling sedikit adalah penduduk dengan pekerjaan sebagai nelayan sebanyak 29 orang $(5 \%)$. Distribusi jumlah penduduk berdasarkan jenis pekerjaan, dapat dilihat pada gambar 2 di bawah ini :

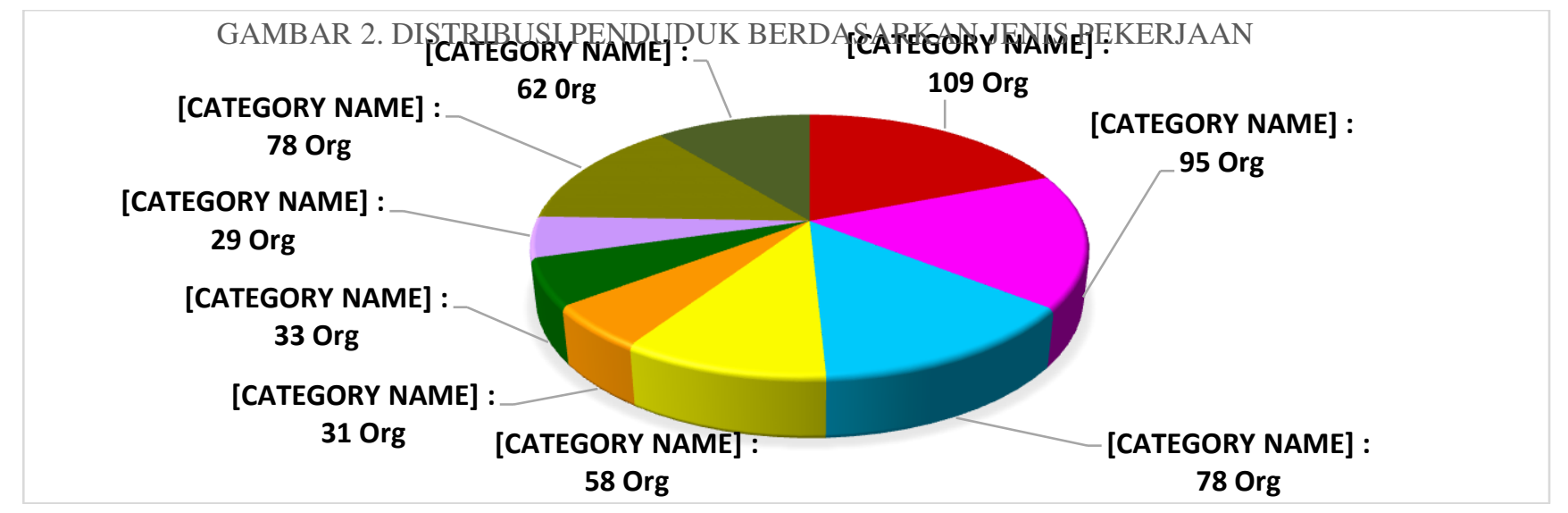

2. Kepemilikan Jamban Di Desa Taloarane I Kecamatan Manganitu

Di Desa Taloarane I dari 182 rumah, masih terdapat 45 rumah $(9,3 \%)$ yang belum memiliki jamban keluarga, yang tersebar di Lindongan/Lingkungan I sampai dengan Lindongan/Lingkungan III.

3. Analisis Variabel Penelitian a. Jenis Jamban
Hasil pengolahan dan analisis data untuk jenis jamban yang dibangun oleh pemerintah Desa Taloarane I Kecamatan Manganitu $100 \%$ adalah jamban leher angsa

b. Konstruksi Jamban

Hasil pengolahan dan analisis data untuk konstruksi jamban yang dibangun 
oleh pemerintah Desa Taloarane I Kecamatan Manganitu $100 \%$ adalah konstruksi jamban memenuhi syarat yaitu jamban memiliki septic tank, memiliki rumah jamban dan tersedia air pembersih yang cukup bahkan lebih yang digunakan oleh anggita keluarga yang menggunakan jamban.

c. Akses Penggunaan Jamban
Akses penggunaan jamban oleh anggota keluarga dari 45 responden, terdapat 9 jamban (20\%) dengan akses ke jamban agak jauh yaitu jamban dibangun sekitar 10 meter bahkan ada yang > 10 meter dan 36 jamban (80\%) jamban dibangun di belakang dan di samping rumah. Akses penggunaan jamban dapat dilihat pada tabel 1 di bawah ini :

Tabel 1. Distribusi Responden Berdasarkan Akses Penggunaan Jamban di Desa Taloarane I Kecamatan Manganitu

\begin{tabular}{ccc}
\hline \multicolumn{1}{c}{ Akses Penggunaan Jamban } & Frekuensi & Persentasi $(\%)$ \\
\hline Terjangkau (jamban di samping/belakang rumah) & 36 & 80 \\
Tidak Terjangkau/Jauh (jamban $\geq 10$ meter) & 9 & 20 \\
\hline Total & 45 & 100 \\
\hline
\end{tabular}

d. Ketersediaan Air bersih dalan Jamban

Hasil pengolahan data untuk ketersediaan air bersih pada setiap jamban $100 \%$ air bersih tersedia dengan cukup dan selalu tersedia pada saat dibutuhkan. Secara fisik air pembersih dalam jamban memenuhi syarat secara fisik (air tidak berwarna, tidak berasa dan tidak berbauh)

e. Perilaku Penggunaan Jamban

Hasil pengolahan data, untuk perilaku penggunaan jamban oleh responden, dapat dilihat pada tabel 2 di bawah ini :

Tabel 2. Distribusi Responden Berdasarkan Perilaku Penggunaan Jamban di Desa Taloarane I Kecamatan Manganitu

\begin{tabular}{lcc}
\hline \multicolumn{1}{c}{ Perilaku Penggunaan Jamban } & Frekuensi & Persentasi (\%) \\
\hline Digunakan & 36 & 80 \\
Jarang digunakan & 6 & 13.3 \\
Tidak Digunakan (BAB) di sungai & 3 & 6.7 \\
\hline \multicolumn{1}{c}{ Total } & 45 & 100 \\
\hline
\end{tabular}

Tabel 2 menjelaskan bahwa, perilaku penggunaan jamban dari responden paling banyak adalah jamban selalu dimanfaatkan oleh anggota keluarga sebanyak 36 responden (80\%) dan paling sedikit adalah jamban tidak digunakan atau tidak dimanfaatkan oleh responden sebanyak 3 responden $(6,7 \%)$ f. Tingkat Kepuasan Terhadap Program STBM Pilar I

Hasil pengolahan data untuk tingkat kepuasan terhadap program STBM khusunya pilar 1, dapat dilihat pada tabel 4 di bawah ini :

Tabel 4. Distribusi Responden Berdasarkan Tingkat Kepuasan Terhadap Program STBM Pilar 1 di Desa Taloarane I Kecamatan Manganitu

\begin{tabular}{lccc}
\hline \multicolumn{1}{r}{ Tingkat Kepuasan } & Frekuensi & Persentasi $(\%)$ \\
\hline Puas & & 36 & 80 \\
Tidak Puas & & 9 & 20 \\
\hline \multicolumn{2}{c}{ Total } & 45 & 100 \\
\hline
\end{tabular}


Tabel 4 menjelaskan bahwa paling banyak merasa puas terhadap program STBM khusunya pilar 1 sebanyak 36 responden (80\%) dan responden yang tidak merasa puas sebanyak 9 responden $(20 \%)$. g. Evaluasi Keberhasilan Program STBM Pilar
I

Hasil pengolahan data untuk evaluasi terhadap keberhasilan program STBM Pilar 1, dapat dilihat pada tabel 5 di bawah ini :

Tabel 5. Distribusi Responden Berdasarkan Keberhasilan Program STBM Pilar 1 di Desa Taloarane I Kecamatan Manganitu

\begin{tabular}{|c|c|c|}
\hline Tingkat Keberhasilan & Frekuensi & Persentasi (\%) \\
\hline Berhasil & 42 & 93.3 \\
\hline Tidak Berhasil & 3 & 6.7 \\
\hline Total & 45 & 100 \\
\hline
\end{tabular}

Tabel 5 menjelaskan bahwa, hasil pengolahan data membuktikan bahwa program STBM Pilar 1 yang berhasil dinyatakan oleh 42 responden $(93,3 \%)$ dan tidak berhasil dinyatakan oleh 3 orang respoden $(6,7 \%)$.

\section{Pembahasan}

1. Jenis Jamban

Keputusan Menteri Kesehatan No 852 Tahun 2008 tentang strategi nasional sanitasi total berbasis masyarakat, jamban sehat adalah suatu fasilitas pembuangan tinja yang efektif untuk memutuskan mata rantai penularan penyakit. Sementara pengertian kotoran manusia adalah semua benda atau zat yang tidak dipakai lagi oleh tubuh dan yang harus dikeluarkan dari dalam tubuh. Zat-zat yang harus dikeluarkan dari dalam tubuh ini berbentuk tinja, air seni dan $\mathrm{CO}_{2}$ (Blegur dan Purnama, 2014).

Hasil pengolahan dan analisis data untuk jenis jamban yang dibangun oleh pemerintah Desa Taloarane I Kecamatan Manganitu $100 \%$ adalah jamban leher angsa dan memenuhi syarat kesehatan. Jumlah jamban yang dibangun sebanyak 45 jamban yang dibangun pada rumah yang tidak memiliki jamban yang tersebar di 3 (tiga) Lindingan/Lingkungan di Desa Taloarane I Kecamatan Manganitu.

Hasil penelitian ini sejalan dengan penelitian yang dilakukan oleh Setyawati (2012) dengan hasil penelitian yaitu $100 \%$ jamban yang dibangun sebagai sarana untuk STBM adalah jamban dengan tipe leher angsa. Penelitian yang sama yang dilakukan oleh Satyani dan Dwipayanti (2012) yang membuktikan bahwa masyarakat merasa puas dengan pembangunan jamban dengan tipe leher angsa.

\section{Konstruksi Jamban}

Bangunan jamban adalah tempat yang dipakai manusia untuk melepaskan hajatnya. Adapun syarat-syarat yang harus dipenuhi untuk mendirikan jamban ialah : a) Harus tertutup, dalam arti bangunan tersebut terlindungi dari pandangan orang lain, terlindung dari panas atau hujan serta terjamin prifasinya. Dalam kehidupan seharihari, syarat ini dipenuhi dalam bentuk mengadakan ruangan sendiri untuk jamban dirumah ataupun mendirikan rumah kakus pekarangan. b) Bangunan jamban ditempatkan pada lokasi yang tidak sampai menganggu pandangan, tidak menimbulkan bau serta tidak menjadi tempat hidupntya berbagai macam binatang. c) Bangunan jamban mempunyai lantai yang kuat, mempunyai tempat berpijak yang kuat yang terutama harus dipenuhi jika mendirikan kakus model cemplung. d) Mempunyai lubang kloset yang kemudian melalui saluran tertentu dialirkan pada sumur penampungan dan atau sumur rembesan yang terutama diisyaratkan jika mendirikan kakus model pemisahan bangunan kakus dengan tempat penampungan dan atau rembesan. e) Menyediakan alat peembersih (air ataupun kertas) yang cukup sedemikian rupa sehingga 
dapat segera dipakai setelah melakukan buanga kotoran (Azwar, 1990).

Hasil pengolahan dan analisis data untuk konstruksi jamban yang dibangun oleh pemerintah Desa Taloarane I Kecamatan Manganitu $100 \%$ adalah konstruksi jamban memenuhi syarat yaitu jamban memiliki septic tank, lantai jamban dan memiliki rumah jamban serta tersedia air pembersih yang cukup bahkan lebih yang digunakan oleh anggita keluarga yang menggunakan jamban.

Sejalan dengan penelitian yang dilakukan oleh Kumarijati (2006), membuktikan bahwa sebagia besar jamban yang dibangun dengan konstruksi jamban yang memenuhi syarat sangat bermanfaat bagi masyarakat pengguna jamban tersebut. Penelitian yang sama yang dilakukan oleh Pebriana, dkk (2012) dan Melviana, dkk (2014) mebuktikan konstruksi jamban yang tidak memenuhi syarat akan sangat berpengaruh terhadap pencemaran sumber air di sekitar jamban.

Menurut Entjang (2000), konstruksi jamban yang terdiri dari 1) Rumah jamban yang mempunyai fungsi untuk tempat berlindung pemakainya dari pengaruh sekitarnya. Baik ditinjau dari segi kenyamanan maupun estetika. 2) Konstruksinya disesuaikan dengan keadaan tingkat ekonomi rumah tangga. 3) Lantai jamban, yang berfungsi sebagai sarana penahan atau tempat pemakai yang sifatnya harus baik, kuat dan mudah dibersihkan serta tidak menyerap air. Untuk konstruksinya juga disesuaikan dengan bentuk rumah jamban. Slap (tempat kaki berpijak waktu si pemakai jongkok). 4) Clocet (Lubang tempat feces masuk). 5) Pit (Sumur penampungan feces) Pit adalah rangkaian dari sarana pembuangan tinja yang fungsinya sebagai tempat mengumpulkan kotoran atau tinja. Konstruksinya dapat berbentuk sederhana berupa lubang tanah saja. 6) Bidang resapan. Bidang resapan adalah sarana terakhir dari suatu system pembuangan tinja yang lengkap ntuk mengalirkan dan meresapkan cairan yang bercampur kotoran atau tinja

3. Akses Penggunaan Jamban
Akses terhadap fasilitas sanitasi yang layak merupakan hal yang penting dalam menunjang peningkatan derajat kesehatan di masyarakat, sanitasi yang layak yang dimaksud disini adalah jamban/WC. Dengan tersedianya jamban yang sehat dapat memenuhi syarat kesehatan sehingga dapat terhindar dari penyebaran penyakit. Pengaruh jamban yang tidak sehat dapat berdampak buruk pada kesehatan, salah satunya dapat menyebabkan penularan penyakit, seperti penyakit diare, muntah berak, dan banyak penyakit lainnya sehingga dapat membawa efek terhadap penurunan tingkat kesehatan. Pemerintah Indonesia juga telah membuat sebuah kebijakan masalah lingkungan yang ada di masyarakat teruma masalah tentang sanitasi yang diatur dalam Peraturan Menteri Kesehatan Nomor 3 tahun 2014 Dimana dalam peraturan tersebut menjelaskan tentang lima pilar STBM yang fokusnya saat ini masih berada pada pilar satu yaitu "Stop Buang Air Besar Sembarangan”.

Jamban yang dibangun oleh pemerintah Desa Taloarane I, harus dapat dijangakau oleh setiap anggota keluarga yang menggunakan jamban. Hasil wawancara dengan responden dimana sebagian besar responden menyatakan bahwa jamban yang dibangun dekat dengan rumah tinggal atau hanya di belakang atau di samping rumah, tetapi ada beberapa responden menyatakan bahwa jamban yang dibangun agak jauh adri rumah yaitu berjarak $\geq 10$ meter hal itu disebbakan oleh lahan yang ada di sekitar rumah sudah tidak layak untuk dibangun jamban sehingga waktu menggunakan jamban memerlukan waktu yang cukup lama.

Hasil pengolahan data untuk akses penggunaan jamban oleh anggota keluarga dari 45 responden, terdapat 9 jamban $(20 \%)$ dengan akses ke jamban agak jauh yaitu jamban dibangun sekitar 10 meter bahkan ada yang > 10 meter dan 36 jamban (80\%) jamban dibangun di belakang dan di samping rumah. Hasil observasi di lapangan dimana sebagian besar Desa Taloarane I adalah bebatuan

4. Ketersediaan Air bersih dalan Jamban

Bagi manusia kebutuhan akan air sangat mutlak karena sebenarnya zat 
pembentuk tubuh manusia sebagian besar terdiri dari air yang jumlahnya sekitar $73 \%$ dari bagian tubuh. Air didalam tubuh manusia berfungsi sebagai pengangkut dan pelarut bahan-bahan makanan yang penting bagi tubuh. Misalnya untuk melarutkan oksigen sebelum memasuki pembuluh darah yang ada disekitar alveoli (Mulia,2005). Sehingga untuk mempertahankan kelangsungan hidupnya manusia berupaya mendapatkan air yang cukup bagi dirinya. Dalam menjalankan fungsi kehidupan seharihari manusia sangat tergantung pada air, karena air dipergunakan pula untuk mencuci, membersihkan peralatan, mandi dan lain sebagainya.

Air merupakan faktor penting dalam pemenuhan kebutuhan vital bagi mahluk hidup diantaranya sebagai air minum atau keperluan rumah tangga lainnya.Air yang digunakan harus bebas dari kuman penyakit dan tidak mengandung bahan beracun. Ditinjau dari segi kualitas (Mutu) air secara langsung atau tidak langsung pencemaran akan berpengaruh terhadap kualitas air. Sesuai dengan dasar pertimbangan penetapan kualitas air minum, usaha pengelolaan terhadap air yang digunakan oleh manusia sebagai air minum berpedoman pada standar kualitas air terutama dalam penilaian terhadap produk air minum yang dihasilkannya, maupun dalam merencanakan system dan proses yang akan dilakukan terhadap sumber daya air.

Hasil pengolahan data untuk ketersediaan air bersih pada setiap jamban $100 \%$ air bersih tersedia dengan cukup dan selalu tersedia pada saat dibutuhkan. Secara fisik air pembersih dalam jamban memenuhi syarat secara fisik (air tidak berwarna, tidak berasa dan tidak berbauh)

5. Perilaku Penggunaan Jamban

Skinner (1938) seorang ahli psikologi dalam Masjuniarty (2010), mengemukakan bahwa perilaku adalah hasil hubungan antara perangsang (stimulus) dan tanggapan (respon).Perilaku dari pandangan biologis merupakan suatu kegiatan/aktivitas organisme yang bersangkutan. Jadi perilaku manusia pada hakekatnya adalah suatu aktivitas dari manusia itu sendiri.
Menurut Robert Kwick (1974) perilaku adalah tindakan atau perbuatan suatu organisme yang dapat diamati dan bahkan dapat dipelajari. Didalam proses pembentukan atau perubahan perilaku dipengaruhi oleh beberapa faktor yaitu faktor intern dan faktor ekstern. Faktor intern mencakup pengetahuan, kecerdasan, persepsi, emosi, motivasi dan sebagainya yang berfungsi untuk mengolah rangsangan dari luar, sedangakan faktor ekstern meliputi lingkungan sekitar, baik fisik maupun non fisik seperti iklim, manusia, sosial-ekonomi, kebudayaan dan sebagainya. Jadi, perilaku adalah suatu pengorganisasian proses-proses psikologis oleh seorang yang memberikan predisposisi untuk melakukan respon menurut cara tertentu terhadap suatu obyek (Masjuniarty, 2010).

Teori L. Green (dalam Soekidjo Notoatmodjo, 2003) mengemukakan bahwa perilaku itu dibentuk oleh 3 faktor ; Faktor predisposisi (Predisposing factors) yang terwujud dalam pengetahuan, sikap, kepercayaan, keyakinan dan nilai-nilai; Faktor pendukung (Enabling factors) yang terwujud dalam lingkungan fisik, tersedianya fasilitas aatu sarana dan prasarana kesehatan; Faktor pendorong (Reinforcing factors) yang terwujud dalam sikap dan perilaku tokoh masyarakat (toma), tokoh agama (toga) serta petugas kesehatan yang merupakan kelompok referensi dari perilaku masyarakat (Masjuniarty, 2010).

Hasil pengolahan data, untuk perilaku penggunaan jamban oleh responden, paling banyak adalah jamban selalu dimanfaatkan oleh anggota keluarga sebanyak 36 responden $(80 \%)$, jarang digunakan oleh responden sebanyak 6 orang $(13,3 \%)$ dan paling sedikit adalah jamban tidak digunakan atau tidak dimanfaatkan oleh responden sebanyak 3 responden $(6,7 \%)$.

Hasil wawancara dengan responden dimana sebanyak 13,3\%, responden jarang menggunakan atau membuang air besar di jamban karena ada anggota keluarga yang tidak terbiasa membuang tinja di jamban dan anggota keluarga tersebut membuang tinja di sungai. 
Hasil penelitian ini sejalan dengan penelitian yang dilakukan oleh Sarmani (2013) dengan hasil penelitian yaitu pengetahuan responden sangat berpengaruh terhadap penggunaan jamban keluarga. Dari 71 responden, terdapat 44 responden dengan pengetahuan yang kurang $79,5 \%$ mempunyai perilaku penggunaan jamban yang kurang baik. Hasil penelitian yang sama dilakukan oleh Masjuniarty (2010), dengan hasil penelitian yaitu $55,2 \%$ jamban yang dibangun tidak digunakan oleh responden. Sejalan dengan penelitian yang dilakukan oleh Pane (2009) dengan hasil penelitian yaitu 55,2\% responden membuang tinja di sungai.

Hasil wawancara dengan petugas puskesmas dan pemerintah Desa Talaorane I, dimana petugas selalu memberikan penyuluhan kepada masyarakat untuk merubah perilaku tentang pemanfaatan jamabn yang sudah dibangun oleh pemerintah. Kegiatan penyuluhan yang dilakukan oleh petugas Petugas Puskesmas dilakukan setiap sebulan 1 kali yaitu dilasanakan pada saat pelaksnaan posyandu di Desa.

6. Tingkat Kepuasan Terhadap Program STBM Pilar I

Sanitasi Total Berbasis Masyarakat (STBM) atau dikenal juga dengan nama Community Lead Total Sanitation (CLTS) merupakan program pemerintah dalam rangka memperkuat upaya pembudayaan hidup bersih dan sehat, mencegah penyebaran penyakit berbasis lingkungan, meningkatkan kemampuan masyarakat, serta mengimplementasikan komitmen pemerintah untuk meningkatkan akses air minum dan sanitasi dasar berkesinambungan dalam pencapaian Millenium Development Goals (MDGs).

Hasil pengolahan data untuk tingkat kepuasan terhadap program STBM khusunya pilar 1, paling banyak merasa puas terhadap program STBM khusunya pilar 1 sebanyak 36 responden $(80 \%)$ dan responden yang tidak merasa puas sebanyak 9 responden (20\%).

Hasil wawancara dengan responden yang merasa puas dengan program STBM dimana program ini sangat membantu masyarakat, khusunya masyarakat yang tingkat ekonomi renda yang tidak bisa membangun jamban, sehingga jamban telah disediakan oleh pemerintah. Bagi masyarakat yang tidak merasa puas $(20 \%$ disebabkan karena masyarakat belum menikmati setiap fasilitas yang disediakan oleh pemerinta. Hal ini disebabkan oleh perilaku masyarakat yang tidak terbiasa dengan penggunaan jamban.

Sejalan dengan hasil penelitian yang dilakukan oleh Setyawati (2012), hasil penelitian ini membuktikan bahwa sebagian besar responden merasa puas terhadap program STBM pilar $1(73,5 \%)$. Penelitian yang sama dilakukan oleh Satyani dan Dwipayanti (2012) dengan hasil penelitian yaitu masyarakat merasa puas dengan pelaksanaan program STBM bagi masyarakat.

7. Evaluasi Keberhasilan Program STBM Pilar I

Keberhasilan program STBM bagi masyarakat khusunya pilar 1 yaitu stop buang air besar sembarangan, dievaluasi dari kepemilikan jamban di Desa Taloarane I (100\%) memiliki jamban dimana dari 45 rumah yang tidak memiliki jamban hasil STBM semua rumah sudah memiliki jamban dan telah dilakukan deklarasi Stob BABS bagi masyarakat Desa Taloarane I Kecamatan Manganitu. Terjadinya perubahan perilaku masyarakat terhadap membuangan tinja atau kebiasaan membuang air besar di sungai, setelah dilakukan deklarasi stop BABS, $80 \%$ masyarakat membuang tinja di jamban dan hanya $20 \%$ masyarakat yang masih membuang tinja di sungai.

Petugas Puskesmas dan pemerinta Desa Taloaranae I masih berupaya untuk melakukan pendekatan bagi masyarakat yang belum terbiasa menggunakan jamban sebagai tempat pembuangan tinja melalui pendekatan secara perseorangan, dengan harapan terjadi perubahan perilaku dalam hal pembuangan tinja. 


\section{Kesimpulan}

1. Jenis jamban yang dibangun melalui program STBM $100 \%$ adalah jamban leher angsa

2. Konstruksi jamban yang dibangun melalui program STBM $100 \%$ adalah konstruksi jamban memenuhi syarat yaitu jamban memiliki septic tank, memiliki rumah jamban dan tersedia air pembersih yang cukup.

3. Akses penggunaan jamban $80 \%$ mempunyai akses yang baik dan 20\% dengan akses ke jamban agak jauh yaitu jamban dibangun sekitar 10 meter bahkan ada yang $>10$ meter

4. Ketersediaan air bersih dalan jamban $100 \%$ air bersih tersedia dengan cukup dan selalu tersedia pada saat dibutuhkan.

5. Perilaku penggunaan jamban yaitu $80 \%$ jamban yang dibangun digunakan $13,3 \%$ jamban jarang digunakan dan $6,7 \%$ jamban tidak digunakan.

6. Tingkat kepuasan terhadap program STBM Pilar I yaitu $80 \%$ responden merasa puas dan 20\% responden tidak merasa puas.

7. Evaluasi keberhasilan Program STBM Pilar I yaitu 93,3\% program STBM berhasil dan hanya $6,7 \%$ program STBM tidak berhasil.

\section{Saran}

1. Bagi Puskesmas Manganitu agar selalu melakukan evaluasi bagi masyarakat yang masih membuang tinja di sungai, dan selalu memberikan penyuluhan tentang bahaya serta dampak buruk bagi kesehatan dan lingkungan jika membuang tinja di sungai.

2. Bagi Pemerintah Desa Taloarane I Kecamatan Manganitu agar memberikan pendampingan, teguran dan sanksi bagi masyarakat yang selalu membuang tinja di sungai.

3. Bagi masyarakat Desa Taloarane I Kecamatan Manganitu agar menjaga dan memelihara setiap fasilitas (jamban) yang sudah dibangun oleh pemerinta, agar sarana tersebut dapat dimanfaatkan dengan baik.

\section{Daftar Pustaka}

Azwar, A. 1990. Pengantar Ilmu Kesehatan Lingkungan. Penerbit Mutiara Sumber Widya, Jakarta.
Blegur A. Y dan Purnama I. G. H. 2014. Evaluasi Pencapaian Program Sanitasi Total Berbasis Masyarakat Pilar Pertama di Wilayah Kerja Puskesmas Kawangu Kab. Sumba Timur. Ilmu Kesehatan Masyarakat, Fakultas Kedokteran Universitas Udayana.

Depkes RI, 2008., Sanitasi Total Berbasis Masyarakat., Ditjen P2PL Informasi

Depkes RI, 2008., Informasi Pengendalian Penyakit dan Pernyehatan Lingkungan Pemukiman. Ditjen P2PL Informasi.

Entjang, Indan. 2000. Ilmu Kesehatan Masyarakat. PT. Citra Aditya Bakti, Bandung.

Juniar M. 2013. Studi Tentang Implementasi Program Sanitasi Total dan Pemasaran Sanitasi (StoPs) dalam Perspektif Deliberatif di Desa Ngampungan Kecamatan Bareng Kabupaten Jombang. Jurnal Kbijakan Manajemen Publik, Vol. 1, No. 1, Januari 2013.

Juniantin V.D, Utami. S dan Witcahyo E. 2014. Kajian Pelaksanaan Program Sanitasi Total Berbasis masyarakat di Desa Jelbuk Kecamatan Jelbuk Kabupaten Jember Tahun 2014. FKM, Universitas Jember.

Kemenkes RI. No. 852/Menkes/SK/IX/2008, tentang Strategi Nasional Sanitasi Total Berbasis Masyarakat

Kemenkes RI, Nomor. 66 Tahun 2014. Peraturan Pemerintah Tentang Kesehatan Lingkungan

Kumarijati E.N. 2006. Hubungan Faktor Konstruksi, Sanitasi Lingkungan dan Kebiasaan Masyarakat Dengan Kualitas Air Sumur Gali Umum dan Diare Serta Upaya Pengelolaannya. Studi Di Kecamatan Jenu Kabupaten Tuban Tahun 2006. Program Magister, Program Studi Administrasi Dan Kebijakan Kesehatan, Fakultas Kesehatan Masyarakat, Universitas Indonesia. Jakarta.

Masjuniarty. 2010. Perilaku Masyarakat Tentang Pemanfaatan Jamban Keluarga Di Wilayah Kerja Puskesmas Cangadi Kec. Liliriaja Kab. Soppeng. Fakultas Ilmu Kesehatan UIN Alaudin Makassar

Nugraha M.F. 2015. Dampak program Sanitasi Total Berbasis Masyarakat (STBM) Pilar Pertama di Desa Gucialit Kecamatan Gucialit Kabupaten Lumajang. Fisip, Universitas Airlangga. Surabaya. 
Rumajar, dkk. Analisis Tingkat Keberhasilan,

Pebriana R. A., Dharma S, dan Naria E, 2012. Faktor-Faktor Yang Berhubungan Dengan Penggunaan Jamban Keluarga dan Kejadian Diare Di Desa Tualang Sembilar Kec. Bambel Kab. Aceh Tenggara. FKM, Universitas Sumatera Utara.

Pane E. 2009. Pengaruh Perilaku Keluarga Terhadap Penggunaan Jamban. Jurnal Kesehatan Masyarakat Nasional Vol. 3, No. 5, Apri; 2009.

Setyawati L. 2012. Evaluasi Program Sanitasi Total Berbasis Masyarakat Dalam Kepemilikan Jamban Di Desa Bungin Kecamatan Tinankung Kab. Banggai

Kepulauan Prov. Sulawesi Tengah. Prodi Kesehatan Masyarakat, Universitas Gorontalo.

Sayani H. A dan Dwipayanti N. M. U. 2013. Analisis Kepuasan Masayarkat Terhadap Program Sanitasi Total Berbasis Masyarakat Di Dusun Muntigunung, Desa Tianyar Barat Kec. Kubu Kab. Karangasem.

Sarmani I. 2013. Faktor-Faktor Yang Berhubungan Dengan Penggunaan Jamban Di Gampong Pawoh Kecamatan Susoh Kab. Aceh barat Daya. FKM Universitas Teuku Umar Meulaboh Aceh Barat 